\title{
THE ABYSSAL CIRCULATION OF THE OCEAN
}

A SYMPOSIUM on "The Abyssal Circulation of the Ocean" was held at the General Assembly of the International Union of Geodesy and Geophysics in Toronto during September 5-6. So very little positive knowledge exists about the nature of the deep circulation that it is possible to maintain entirely different points of view. G. A. Riley (United States) reviewed the steady-state theory, proposed some thirty years ago by Merz, Defant and Wüst. This view appears to be partially confirmed by F. C. Fuglister's (United States) recent re-survey in Crawford of two original profiles across the South Atlantic by Meteor in 1925-27. As Fuglister showed, there is little observable change in either the temperature or salinity of the deep waters in the northern South Atlantic over the thirty-year interval (in the Deep Water of both eastern and western troughs there is a decrease of temperature of less than $0.04^{\circ} \mathrm{C}$. and an increase of salinity of less than 0.04 per mille, and in the Bottom Water of the western trough an increase of both temperature and salinity of about $0.02^{\circ} \mathrm{C}$. and 0.02 per mille). On the other hand, L. V. Worthington (United States) maintains, on the basis of what appears to be a general decrease of concentration of dissolved oxygen in the deep waters of the Atlantic between $50^{\circ} \mathrm{N}$. and $16^{\circ} \mathrm{S}$. since about 1925, that the deep water of the North Atlantic (below 2,000-m. depth) is now isolated from the surface and is no longer being renewed during the winter by sinking water masses off Greenland as is generally supposed. L. H. N. Cooper (United Kingdom) presented evidence that corrosion products in reversing water bottles may absorb oxygen from sea-water at a serious rate, and that with a new set of bottles, erratic variations in concentration of deep-water oxygen may occur near a continental slope. Thus Cooper holds that judgment may need to be suspended on Worthington's conclusions, based as they are on oxygen data. Riley believes that the North Atlantic deep waters have never been wholly depleted of oxygen in the geological past, so that it is unlikely that at present there can be very large fluctuations in oxygen content. It is difficult to reconcile this view with the quite firm indication to the contrary shown by Worthington's data.

The new hydrographic surveys of the North Atlantic by Discovery II and Atlantis were made using the new Schleicher-Bradshaw salinity bridge instead of the traditional salinity titration determination method. Thus a new high degree of resolution in the functional relation between salinity and temperature (the $T-S$ relation) has been disclosed. The reason for such a relationship has always been completely obscure; however, N. P. Fofonoff's (Canada) new studies of the effect of the non-linearities of the equation of state of sea-water on the vertical stability and mixing appear to indicate ways in which this hitherto mysterious relationship may be explained.

One hopes that the new interest in the ocean on the part of the geochemists will result in many helpful geochemical studies of the distribution of rather esoteric properties of sea-water which may shed light on the problem of the circulation. In fact, it was suggested that it might be a good idea to try to organize, under international auspices, a world geochemical expedition to explore the entire world. ocean, and to procure a special ship and other necessary equipment. W. C. Broecker and his collaborators (United States) presented recent measurements of carbon-14 made at the Lamont Geological Observatory from water samples at a number of positions in the North Atlantic Ocean, indicating a mean residence-time of 650 years for deep water in the North Atlantic and also a rather large lateral mixing sufficient to produce nearhomogeneity of carbon-14 over the deep North Atlantic. F. Koczy (United States) estimated values of the vertical eddy diffusivity from measurements of the vertical distribution of radium over the deep ocean floor. The use and implications of the distributions of particle content as an indicator of water mass were described by N. G. Jerlov (Sweden), and of the ratio of oxygen-18 to oxygen-16 as an indicator of source of water by B. Benson (United States). A. C. Redfield (United States) described the relation of the phosphorus content of the world-ocean to its general circulation, and presented a chart of the distribution of phosphates at 2,000-m. depth over the world-ocean.

H. Mosby (Norway) and J. Eggvin (Norway) described conditions in the Norwegian Sea, and G. Dietrich (Germany) the occasional floods of Norwegian Sea water which spill over the submarine ridges separating the Norwegian Sea from the rest of the Atlantic. L. V. Worthington pointed out that the view that these overpourings can contribute directly to the formation to-day of North Atlantic deep water seems doubtful on the basis of the new section along $50^{\circ} \mathrm{N}$. made by Discovery $I I$. On the other hand, there is direct observational evidence of a rather vigorous circulation in the deep water (J. C. Swallow and L. V. Worthington, Nature, 179, 1183 ; 1957) as a result of the measurements of the deep western boundary current under the Gulf Stream made by Discovery $I I$ and Atlantis last Spring; and G. Wüst's (Germany) new computations show high rates of transport in the deep water of the South Atlantic as well.

A map discussion centred about the preparation of a chart of temperature, salinity and dissolved oxygen content at 4,000-m. depth, constructed by E. D. Stroup (United States), and rough working copies were distributed to all participants. This chart contains all the deep data yet published and it is hoped that it will prove helpful to those planning future oceanographic surveys. A chart of temperature, salinity and oxygen content of the Pacific at the $5,000-\mathrm{m}$. level was presented by W. Wooster and G. Volkmann (United States).

The general picture emerging from these various descriptive studies is that the general flow of water below 2,000-m. depth in the ocean is directed from quite limited areas in the northern North Atlantic and from the shallow shelf areas surrounding Antarctica into the Indian and Pacific Oceans. The regions where water is supplied by sinking to the level beneath $2,000 \mathrm{~m}$. are doubtless quite small, and probably 
intermittent. On the other hand, the upward flow of water out of the deep ocean evidently occurs in a very widespread manner all over the ocean, and it is presumably this upward flow which prevents the hot water at the surface from gradually working down into the deep water (even at the tropics the warm surface layers are relatively shallow and the temperature of bottom waters is less than $3^{\circ} \mathrm{C}$.). The average time of residence of a particle of water between its introduction into the deep water at a source and its eventual upwelling through the $2,000-\mathrm{m}$. level is estimated at between 400 and 1,200 years. Superposed upon this mean circulation there are evidently rather major perturbations.

A theoretical method for constructing the horizontal field of flow in the abyss was described by $\mathrm{H}$. Stommel (United States), and some experimental studies in a rotating basin, designed to test partially these theoretical ideas, were presented by A. Faller (United States). Unfortunately the three theoretical oceanographers from the U.S.S.R. who were invited to attend the symposium (W. B. Stockmann, P. S. Lineykin and M. Koshljakov) were unable to come to Toronto, but the official delegate, V. G. Kort, kindly read a short abstract of a paper by $M$. Koshljakov, who is of the opinion that the abyssal circulation is essentially produced by wind, that lateral eddy viscosity is of vital importance, and that the deep flows are almost always in the same direction as surface currents. These views are quite the opposite of those expressed by Stommel, who regards the deep circulation as an essentially heat-driven and saltdriven engine, and viscosity as insignificant dynamically. In general, Stommel considers that the surface flows and deep flows are in opposite directions, except in a few instances where the wind-driven surface layers are forced to flow otherwise. This theory predicts that in the deep water the mean meridional components of velocity are everywhere directed poleward except in the western boundary streams which connect the slow central flow to regions of formation of deep water. It is thus possible to predict the deep counter-currents under the Gulf Stream. Similarly, we can now expect to find a very narrow intense northward current between 3,000 and 5,000 m. over the Tonga-Kermadec Trench, which feeds the entire Pacific with deep water. One hopes that the adherents of these two rival theories of abyssal circulation will be able to develop them quantitatively and in sufficient detail so that future direct measurements, such as those using Swallow's neutrally buoyant floats, will effect a clear-cut decision in favour of one or the other. It is in this way that science progresses.

R. B. Montgomery, M. Pollak and J. Cochrane (United States) presented a temperature-salinity diagram showing the frequency of occurrence of waters of various temperatures and salinities in each of the major oceans separately, and combined as a worldocean. Two other theoretical papers, not specifically related to the topic of deep circulation, were read at the Symposium : a study of the formation of multiple currents in flow in a divergent channel under the influence of rotation (B. Saint-Guily, France) and a method for computing actual currents from the geostrophically computed currents in the presence of uniform vertical eddy viscosity (K. Hidaka, Japan). Papers by M. Uda (Japan), K. Yoshida (Japan) and A. E. Maxwell (United States) were read in title only.

H. STOMMEL

\section{NEWS and VIEWS}

\section{The Artificial Earth Satellite}

THE successful launching of an artificial Earth satellite ranks as a technical achievement of the first magnitude and an event of great scientific interest. From the early observations on the $20 \mathrm{Mc}$./s. and $40 \mathrm{Mc} / \mathrm{s}$. signals transmitted by the satellite, the orbit appears to be at a mean altitude of 350 miles with a mean speed of about $24,800 \mathrm{ft}$. $/ \mathrm{sec}$. The orbit is slightly elliptical, in a plane inclined at about $65^{\circ}$ to the equator. It is to be expected that, as a result of the Earth's oblateness, the orbital plane will rotate slowly about the Earth's axis at about $21_{2}^{\circ}$ a day, and in a direction opposite to the Earth's rotation. The major axis of the orbital ellipse will also regress backwards, relative to orbital direction, at less than $\frac{1}{2}^{\circ}$ per day. It is to be hoped that the radio-interferometer observations, coupled with the theoretical orbital data just quoted, will allow the computation of sufficiently accurate orbits to facilitate further accurate observations by optical means.

At the time of writing, it is difficult to forecast the total lifo-time of the satellite since the density of the atmosphere is known only very imprecisely at heights of 250 miles and higher. Assuming a value of $10^{-11}$ times the density at sea-level, one may estimate that a satellite with perigee at 250 miles should survive for about a month. Although theoretical computations of aerodynamic drag, heat protection and heat-sink characteristics suggest that safe re-entry to the Earth's atmosphere should be feasible, recovery of an intact satellite and its instruments is likely to prove a formidable technological problem. The warm congratulations of all those engaged in the applied science of aeronautics and rocket propulsion must go to the Soviet scientists and engineers involved in the satellite project. Future satellite launchings are awaitied with the utmost interest.

\section{Paul Instrument Fund Awards}

Awards of grants by the Paul Instrument Fund Committee have been made as follows: $£ 2,700$ to Prof. G. F. J. Garlick, professor of physics in the University of Hull, to onable him to carry out studies of phosphors and photoconductors with the view of the development of solid state light image amplifiers or converters; $£ 2,000$ to Dr. H. H. Hopkins, senior lecturer in physics (technical optics), Imperial College of Science and Technology, London, for continuation of the construction of a static scanning fibrescope, the aim of which is to provide a flexible unit capable of transporting optical images along its length; $£ 100$ to Dr. D. Gabor, Mullard reader in electronics, Imperial College of Science and Technology, making 